\title{
Conhecer É Agir: Entre a Epistemologia Genética e o Legado de Paulo Freire ${ }^{a}$ Knowing Is Acting: Between Genetic Epistemology and Paulo Freire's Legacy
}

\author{
J ORGE A. GONZÁ LEZ \\ Universidad Nacional Autónoma de México, Centro de Investigaciones Interdisciplinarias en \\ Ciencias y Humanidades. Cidade do México - D.F., México
}

\section{RESUMO}

O que significa se tornar sujeitos do conhecimento? Atores sociais que enfrentam seus problemas por meio da construção de conhecimentos realmente se empoderam? A teoria e os achados da Epistemologia Genética fornecem uma poderosa ferramenta teórica e metodológica para compreender experiências de conscientização como processos de empoderamento, e permitem ler o método freiriano de alfabetização à luz de uma teoria dos processos de construção do conhecimento. Ao estudar e praticar a Comunicação para o Desenvolvimento, afirmo que Informação, Comunicação e Conhecimento constituem um processo tríplice e indissociável, que inclui transformações biológicas, comportamentais e sociais, especialmente as que foram criadas coletivamente.

Palavras-chave: Epistemologia genética, pedagogia do oprimido, conhecimento

\begin{abstract}
What does it mean to become subjects of knowledge? Do the social actors who confront problems through knowledge construction really become empowered? The theory and findings of Genetic Epistemology provide a powerful theoretical and methodological tool for understanding experiences of conscientization as processes of empowering, allowing to read the Freirean method for literacy under the light of a theory of the processes of knowledge construction. In studying and practicing Communication for Development, I claim that Information, Communication and Knowledge constitute a crucial threefold, non-separable process that includes biological, behavioural, and social transformations, especially those that have been collectively created.
\end{abstract}

Keywords: Genetic epistemology, pedagogy of the oppressed, knowledge 


\section{INTRODUÇÃO}

STE TEXTO BUSCA estabelecer um diálogo conceitual possível e necessário entre o trabalho de Paulo Freire e alguns dos fundamentos da Epistemologia Genética (EG), que Jean Piaget e seus colaboradores criaram para estudar cientificamente os processos de construção do conhecimento na espécie humana. As perspectivas são complementares e se potencializam dentro do polêmico espaço da comunicação para a mudança social (Badenes, 2020; Downing, 2021; Gumucio \& Tufte, 2008; Tufte, 2017). Para diminuir o efeito da reduzida visibilidade e da instrumentalização que prevalecem nas ciências e, em particular, entre os estudiosos da comunicação, dedicarei um pouco mais de espaço para expor o trabalho de Piaget e García.

Ao final do artigo, apresentarei brevemente uma área de exploração na pesquisa e desenvolvimento da cibercultur@ - KC@ - (González, 2019). Nela, convergem a EG, centrada no estudo dos mecanismos construtivos do conhecimento, considerado como ação sobre o mundo (García, 2000; Piaget \& García, 1982), e a pesquisa/ação, voltada para a melhoria das condições de vida das pessoas, por meio da intervenção coletiva na rede de relações entre a informação, a comunicação e o conhecimento, para conhecer/agir sobre problemas urgentes.

\section{TRENS PARALELOS: DUAS PERSPECTIVAS, DOIS AUTORES, DOIS PROPÓSITOS}

Freire e Piaget são dois dos autores mais utilizados e citados nas áreas da pedagogia, da educação, da psicologia, do ensino e até dos movimentos sociais (Caldart, 2004). Em minha própria formação em comunicação, desde o início dos cursos, líamos ambos os autores (González, 2018, p. 282). A leitura de Freire (1973) me comoveu emocionalmente; a de Piaget (1973), embora tenha achado fascinante, não consegui entender, o que só ocorreu muitos anos depois, graças ao trabalho conjunto com Rolando García.

A compreensão sempre depende da estrutura de quem entende, não apenas do conteúdo a entender.

\section{Freire: Alfabetização pela liberdade}

Freire deixa bem claro que sua pedagogia do oprimido não é apenas um método de aprendizagem instrumental das letras, mas uma forma de práxis social cujo propósito imediato é permitir a capacidade de ler e escrever além de letras e textos, ou seja, uma prática de ler e escrever (ação transformadora) a respeito do mundo social (Freire, 1973, 1993). 
O objetivo não é apenas alfabetizar, mas conscientizar sobre as condições de vida das pessoas por meio da reflexão, do diálogo e da ação. É uma forma de intervenção dialógica, consciente e deliberada, dentro da organização desigual da sociedade. Essa desigualdade se corporifica em milhões de pessoas oprimidas que permanecem imersas em uma atmosfera de ignorância, autodesprezo fatalista e incapacidade de se organizar coletivamente para mudar as relações que fazem que o mundo dos analfabetos, dos despossuídos, dos cultural e economicamente empobrecidos seja vivido e concebido dessa forma e não de outra. Freire busca a transformação dessa situação e da miserável condição de milhões, que é vivida e perdura em cada comunidade, em cada favela, em cada agroindústria, em cada fábrica, nas ruas sob as pontes e nos campos agrícolas criados no decorrer da história.

É a pobreza que está por trás da inacessibilidade à leitura e à escrita - e não o contrário, como muitas vezes se pensa (Dale \& Hyslop-Margison, 2010) ou seja, eles não são pobres porque são analfabetos, mas o contrário. O método de Freire desenvolve a apropriação desse poderoso artefato cultural (Vygotski \& Luria, 2007), que permitiria aos alunos/educadores modificar sua reflexão e ação, não apenas como indivíduos, mas também como coletivos.

Uma característica importante do horizonte utópico da proposta de Freire é o fato de que, libertando-se como oprimidos, também se liberta o opressor:

A violência dos opressores que os faz também desumanizados, não instaura uma outra vocação - a do ser menos. Como distorção do ser mais, o ser menos leva os oprimidos, cedo ou tarde, a lutar contra quem os fez menos. E esta luta somente tem sentido quando os oprimidos, ao buscar recuperar sua humanidade, que é uma forma de criá-la, não se sentem idealistamente opressores, nem se tornam, de fato, opressores dos opressores, mas restauradores da humanidade em ambos. E aí está a grande tarefa humanista e histórica dos oprimidos - libertar-se a si e aos opressores. (Freire, 1968/2005, p. 41)

Não é com uma relação de ódio e destruição que se confronta e rompe a opressão. É com a construção da importância do outro, do próximo como eu mesmo que se reelabora virtualmente uma visão crítica do nefasto mundo de exploração, de violência, de abuso e de injustiça, que não têm nada de naturais.

Essas condições foram criadas na história e, portanto, são mutáveis.

A proposta pedagógica e política de Freire é baseada na ética (Dussel, 1998), nos valores humanos (Paoli, 2014), na escuta e na transformação daqueles que se engajam nessa luta, concebida e desejada como uma práxis totalmente libertadora.

De forma prática, com o tempo, a pedagogia do oprimido também é transmutada em uma pedagogia da esperança, ou seja, no prenúncio de outro mundo e 
outras relações possíveis, como princípio que norteia as ações cotidianas, apesar de as relações sociais injustas continuarem a drenar a energia social para aquela zona sombria, densa, pesada e profundamente injusta que é a exploração econômica, bem como as várias formas de dominação política e subalternidade cultural.

Ser pobre é ser um sujeito social desenergizado socialmente, não pela natureza, mas pela natureza das relações sociais e por uma história que escapa de sua consciência. Essas relações de exploração, de violência, de desapropriação e extração de energia social, que subjugam e degradam aqueles a quem Freire chama de oprimidos, também degradam e desumanizam, claro, o explorador, e são instiladas, aprendidas (e podem ser combatidas) na forma de valores desde o nascimento (Paoli, 2014, p. 12). Também é bastante compreensível a relação muito próxima entre a pedagogia de Freire e a Teologia da Libertação: "o cuidado só surge quando a existência de alguém é importante para mim" (Boff, 2014, p. 103). Ou como nos dizia uma líder [comunitária] do Nordeste do Brasil: "se os outros estão bem, eu estou melhor" (Krohling-Peruzzo \& González, 2018, pp. 205-235). O amor ao próximo, compreendido dessa forma, liberta. Essa é a proposta e a justificativa do trabalho de Freire.

Por essas e outras razões, além de estabelecer um método de alfabetização de adultos, o trabalho de Freire constitui uma filosofia moral, uma reformulação no código amoroso e, precisamente por isso, relações plenamente políticas com a vida, com os outros e com o mundo. Daí a importância de compreendê-lo também como uma pedagogia da autonomia (Freire, 1996/2010), que exige a formação de um determinado tipo de professor que deve se preparar para desenvolver esse processo em todas as atividades e exercício de sua profissão.

Freire conduziu muitas experiências concretas de alfabetização na América Latina e em outras partes do mundo. Seu legado continua presente não apenas como um método prático de aprender a ler e escrever, mas como um guia na organização social.

Vamos, agora, rever com mais detalhes algumas características da Epistemologia Genética.

\section{Piaget: Conhecer o processo de conhecer}

Desde meados do século passado, Piaget, biólogo por formação, psicólogo "por necessidade" e epistemólogo por vocação, com uma equipe multidisciplinar que se reúne no Centre International d’épistémologie Génétique, na Université de Genève, inicia a base conceitual e a verificação empírica de uma nova ciência: a Epistemologia Genética. O adjetivo genética é inserido por Piaget para diferenciá-la da epistemologia desenvolvida como um ramo da 
filosofia especulativa, que explorou desde tempos antigos as questões sobre $o$ que é e de onde vem o conhecimento.

A piagetiana, ao contrário da epistemologia filosófica, toma a tarefa de verificar, a partir de evidências empíricas, suas conceitualizações sobre o processo de conhecimento. Piaget rejeita as indagações sobre a origem ou essência desse conhecimento e constrói, ao longo de várias décadas, uma disciplina para estudar outras questões cientificamente mais produtivas: como se vai de uma estrutura de conhecimento menos diferenciadora para outra mais diferenciadora?

Sua epistemologia é genética - não devido à sua relação com genes. $\mathrm{O}$ adjetivo é usado por Piaget para enfatizar que o que interessa saber em detalhes é o que uma estrutura de conhecimento/ação anterior deixa como herança a outra, no tempo, e como essa transformação se realiza.

Piaget concentrou-se no desenvolvimento e na base conceitual de uma disciplina experimental que tinha seu próprio domínio, objeto e método, ao mesmo tempo que elaborava uma teoria logicamente coerente e empiricamente verificável dos processos de conhecimento.

O projeto de alfabetização que Freire criou e desenvolveu inicialmente no Nordeste brasileiro teve, desde o início, um horizonte de ação transformadora das condições de vida desumanas da população mais pobre, dos oprimidos. Freire parte de um claro compromisso político e prático, um horizonte de crítica e possível transformação das condições de miséria que geraram a desumanização e o analfabetismo de milhões.

Aparentemente, não tem nada a ver com Piaget, nascido e educado na sociedade suíça de língua francesa, que se propôs a preencher uma lacuna no horizonte científico, criando uma teoria científica dos processos de conhecimento. Piaget não era conhecido por afiliações ou preocupações políticas que impulsionassem seu trabalho. Mas, de maneira controversa, para alcançar seu objetivo, tinha que se opor a duas fortes tradições filosóficas que haviam tratado, muito antes dele, das questões do conhecimento: o inatismo e o empirismo (García, 2000, pp. 45-47).

Em relação à primeira, Piaget é contra defender que o conhecimento surge ou aparece inatamente nas pessoas; ou seja, essa tradição considera que o conhecimento já está inserido em nossa natureza, independentemente da experiência do real.

A EG, por outro lado, mostra que todo o conhecimento é o produto de uma ação construtiva e, portanto, implica um sujeito ativo. Nossa espécie só pode conhecer quando age sobre as coisas e situações do mundo. Sem ação sobre o mundo real, que existe fora de nós, não há conhecimento possível. Não há nada inato nas interações que geram conhecimento. 
A segunda e mais robusta adversária, que é representada por todas as formas de empirismo, especialmente o empirismo lógico ou o neopositivismo do Círculo de Viena -, é criticada porque supõe que a realidade é conhecida através dos sentidos.

Piaget refuta todos os tipos de empirismo porque mostra empiricamente que as características e propriedades dos objetos que podemos perceber (com os sentidos) dependem dos esquemas de relações estabelecidos pelo sujeito em seu desenvolvimento. Ao mesmo tempo, mostra que fazer estudos empíricos não significa ser empirista. O fundamental é entender e explicar os processos estruturantes desses esquemas de relações.

A ciência de Piaget é contraintuitiva: não se aceita facilmente o fato de que só possamos ver empiricamente o que nossos esquemas delimitam.

Em outras palavras, as propriedades que registramos com os sentidos dependem das relações e não o contrário. A famosa frase de Bachelard (1981) faz todo o sentido: “o vetor do conhecimento vai do pensamento ao real e não ao contrário" (p. 11).

Essas posições filosóficas (inatismos e empirismos) sobre o conhecimento e a ciência, que têm sido as mais influentes na história do pensamento ocidental, são questionadas e rejeitadas por Piaget. A primeira por dispensar a experiência e a segunda por superdimensioná-la. Nosso autor mostra empiricamente que as explicações e fundamentos que o empirismo lógico havia elaborado sobre o conhecimento tornaram-se (e ainda são) muito influentes e logicamente impecáveis, mas com a particularidade de serem cientificamente falsas.

O conhecimento é construído, não entra de fora a partir de experiências sensoriais seguidas de generalizações empíricas, mas por meio de sucessivas reformulações causadas por crises permanentes dos esquemas de ação diante de condições às quais não estão adaptados e, por isso mesmo, requerem um sujeito ativo que constrói seu conhecimento em interação com seus objetos, por meio de uma gama de processos de assimilação e acomodação que, desde a adolescência, levam ao desenvolvimento da capacidade de abstração reflexiva. Com isso, torna-se possível a antecipação, as deduções e o desenho do planejamento lógico. Essa disciplina nos explica cientificamente como se constrói, literalmente, a possibilidade de "não apenas buscar o que é bom, mas (que) também se pode buscar o bem, não só o sucesso, mas a compreensão ou a verdade" (Becker, 2017, p. 17). Essa capacidade de desenvolvimento dos seres humanos constitui um salto qualitativo na concepção de mundos possíveis, na reelaboração narrativa da própria memória e na definição crítica do presente, como veremos na parte final. A EG, ao explicar os processos que reorganizam a ação do conhecimento, torna-se inteligível, oferece um apoio rigoroso e desmistificador ao processo que Freire chama de conscientização. Essa conclusão está por trás do adjetivo construtivista, que também é frequentemente aplicado à epistemologia piagetiana. 
Da mesma forma, o EG mostra de maneira impecável que essa interação não pode ser entendida sem uma concepção dialética de todo o processo construtivo, uma vez que é sempre gerada através de sucessivos equilíbrios e reequilíbrios de esquemas de conhecimento em crise.

O conceito de estrutura na EG não é um substantivo, mas deve ser tomado como um verbo. Não há estrutura sem história, assim como não há história sem estrutura, responderia Piaget àqueles que o criticaram como estruturalista.

Só podemos conhecer mediante nossa interação com os objetos, nos tornamos totalmente humanos, ou seja, seres sociais, quando, no decorrer do tempo, desenvolvemos essa capacidade superior de abstração reflexiva em nossas próprias coordenações, que não pertencem ao objeto, não vêm de fora, nem podem ser observadas diretamente.

Trata-se de uma concepção científica revolucionária e sem precedentes na compreensão científica dos processos de conhecimento que pode ter repercussões importantes e bem fundamentadas nos modos de ensino/ aprendizagem e na prática das ciências. Da mesma forma, também pode servir como um suporte teórico e prático nos processos de alfabetização, às vezes perdidos ao lidar com as deficiências dos sujeitos alfabetizáveis, podendo "ajudar o adulto a entender a forma de funcionamento da escrita a partir do que já construiu, a partir de seu conhecimento efetivo e não de sua ignorância" (Ferreiro, 2007, p. 206).

O programa de trabalho de Piaget dedicou décadas ao estudo das fases iniciais da construção do conhecimento. Isso envolveu o desenho de protocolos detalhados para pesquisa com crianças, desde recém-nascidos - com seus próprios filhos - até adolescentes capazes de gerar abstrações complexas, pois essas foram construídas por meio de suas ações de conhecimento a partir de muitos desequilíbrios e reequilíbrios. Quando as crianças, mais ou menos a partir dos 13 ou 14 anos, constroem esse tipo de abstrações, seu sistema cognitivo é desenvolvido, pronto e habilitado para a vida social adulta. Da mesma forma, as diversas inferências e teorizações que Piaget realizou sobre os processos de conhecimento o levaram à invenção da psicologia genética, projetada para estudar a psicogênese dos conceitos e fazer verificações empíricas das conceitualizações de sua epistemologia.

O trabalho científico de Piaget, tanto pelo uso do método histórico-crítico quanto por sua concepção dinâmica dos processos de construção do conhecimento, coloca-o, assim como a obra de Freire, dentro da tradição da dialética de Hegel, Marx e Lênin.

Piaget, como o próprio Karl Marx, também não era um marxista, mas sua concepção e uso da dialética está no centro da parte mais criativa e importante de 


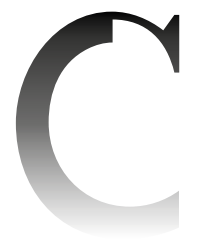

toda sua teoria (García, 2008, p. 202). No entanto, essa epistemologia científica (construtivista/dialética/genética), que foi, desde o início, o objetivo de todo o seu trabalho, parece ter sido enclausurada por um mecanismo seletivo que o rotulou como psicólogo infantil, pedagogo, educador ativo, uma simplificação que faz que as contribuições fundamentais de sua teoria, muitas vezes mutiladas na identificação e superação das etapas de desenvolvimento, sejam ignoradas.

Becker (2017) nos oferece algumas razões para isso:

Nosso sistema escolar é organizado por faixas etárias. Isso facilita a gestão da escola. Acontece que esse princípio administrativo, o agrupamento de alunos por idade, foi transformado em princípio pedagógico.... A teoria de Piaget, quando ingressou na escola, foi interpretada como uma teoria das fases (stage), em vez de ser vista como estados (stade) ou estágios, uma metáfora preferida por muitos. Com isso, todo o processo de equilíbrio ou abstração reflexiva foi reduzido a um processo de maturação. Em uma palavra, anulou sua novidade. Aquilo que deveria ser entendido como um período de desenvolvimento, determinado por toda uma estrutura ativamente construída pelo sujeito, que perdura por um certo tempo - um estado, portanto -, foi interpretado como resultado de um processo de maturação, ou seja, predeterminado no genoma. (pp. 22-23)

A visibilidade e o estudo de Piaget como criador de uma disciplina científica que estuda os processos de construção do conhecimento foram completamente diluídos sob sua visibilidade como psicólogo. É claro que alguns dos campos que podem ser influenciados por essa nova teoria do conhecimento como ação são a educação e pedagogia, a psicologia do desenvolvimento infantil e outros ramos de aplicação que foram gradualmente derivados dos trabalhos

${ }^{1}$ Um deles, por exemplo, é o Inteligência Artificial desenvolvida pelo matemático Seymour Papert quando, após dez anos de colaboração com Piaget, foi recrutado pelo MIT nos Estados Unidos, onde criou a linguagem de programação Logo e promoveu o construcionismo em continuidade à sua prática em Genebra. de Genebra ${ }^{1}$. Em sua consolidação institucional, a reflexão teórica sobre os experimentos e a ativação processual desse objetivo ao longo dos anos, Piaget atraiu uma longa lista de colegas proeminentes: Ilya Prigogine (químico), Benoit Mandelbrot (matemático), Lucien Goldman (sociólogo), Bärber Inhelder (psicólogo), Pierre Greco (linguista), Léo Apostel (filósofo) e Rolando García (físico atmosférico e empiricista lógico), assim como outros que colaboraram com ele no desenvolvimento de sua epistemologia.

\section{O BINÔMIO VIRTUOSO PIAGET-GARCIA}

Como acontece em um bom número de casos na história da ciência, o encontro de Piaget com Rolando García é tão fortuito quanto afortunado para ambos (González, 2018). 
As relações entre o influente Círculo de Viena e o grupo de Genebra, como resultado do próprio desenvolvimento da EG, construída contra as suposições do Empirismo Lógico, não eram as melhores. Para esta nova ciência, todo o empirismo cria um formidável obstáculo epistemológico.

Quando falamos de empirismo, essa perspectiva que basicamente sustenta que o conhecimento depende do que nossos sentidos informam, estamos apontando não apenas um posicionamento filosófico que Piaget demonstrou como empiricamente falso, mas destacamos a existência atual de toda uma estrutura social de relações de poder (pela força dos sistemas de avaliação, contratação e permanência em instituições especializadas, em faculdades e escolas) e de valorização aceitas ou impostas, que definem na prática o que é e não é a ciência, o científico e suas práticas especializadas.

Como se não houvesse disciplina científica sobre os processos de conhecimento, autores empiristas em todas as suas formas e manifestações continuam a ser usados nos cursos de formação dos cientistas e na maioria dos não cientistas no mundo ocidental. Quero dizer que, como corrente filosófica sobre o conhecimento, continua a orientar as avaliações, a estrutura e os conteúdos da produção de textos, as revistas, as editoras, as associações, os programas das disciplinas, as práticas jornalísticas e pedagógicas sobre o significado e o ensino básico do discurso científico, a história dos cientistas e suas descobertas e, claro, a sacralização de um único e verdadeiro Método Científico (tirado de uma etapa da história da física) que se converteu em um cânone. Qualquer disciplina que não seja regida por este método é considerada como mera especulação, crença e subjetividade e, no máximo, como mais uma forma de pseudociência (Bunge, 1983, p. 54).

A Epistemologia Genética nos mostra que não existe um único e infalível método científico, mas diferentes formas de cientificidade (González \& KrohlingPeruzzo, 2019, p. 71) e que a ciência é mais uma forma de conhecimento, mas não é nem a única, nem, por vezes, a mais útil. Também nos mostra que, na metodologia de pesquisa, em vez de se dedicar a perseguir e testar hipóteses, devemos estar preparados para esperar o inesperado.

Várias pré-noções e vícios sobre ciência e conhecimento científico continuam a ser ensinados, são incorporados e defendidos de forma rígida e acrítica por professores e alunos de todas as disciplinas, como se não houvesse há anos uma sólida teoria científica dos processos de conhecimento. Podemos ilustrar essa situação paradoxal de ignorância seletiva com três exemplos.

$\mathrm{Na}$ filosofia, continua-se ensinando a lógica silogística como se não tivesse existido Bertrand Russel e sua metalinguagem formal, que nos faz ver que toda a lógica aristotélica opera com uma única relação (incluído/não incluído), claramente insuficiente diante da ciência moderna. 
$\mathrm{Na}$ química, continua-se entendendo por que as coisas se queimam com fogo por meio da teoria do flogisto de Stahl, como se Lavoisier e sua construção do oxigênio como oxidante não tivessem existido.

Na comunicação, continua-se a ensinar a teoria hipodérmica, como se Katz e Lazarsfeld e a da influência pessoal e comunicação em duas etapas não tivesse existido; por fim, na economia, como se não houvesse Marx e sua teoria da mais valia como uma teoria da falsidade do lucro da economia clássica.

Uma vez que o cânone empirista é imposto e aceito, o quantitativismo também é sacralizado (se o estudo não tem quantidades expressas em matemática, pode ser qualquer coisa, mas não é científico). O movimento oposto, que é igualmente empirista, mas de grau diverso, encerra a disputa em favor do que chamei em outros textos de achismo (eu acho que isso se comporta assim e não preciso de números para compreender) porque - argumentam - a ação humana é como a história, irrepetível e impossível de ser explicada ou quantificada, apenas interpretada, entendida. A EG nos ensina que compreensão e explicação são dois momentos complementares, e não polos opostos, em toda pesquisa.

Ainda assim, muitas instituições universitárias estão divididas internamente entre as ciências e as humanidades, entre as ciências naturais e sociais, entre explicar e compreender, entre a verdade científica e as opiniões sobre a realidade.

Acreditamos que é um erro separar a formação filosófica e a formação em qualquer uma das disciplinas científicas. Ao processo de especialização dos domínios de cada uma delas, do lado dos quantis ou dos qualis, acrescentam-se diferentes fobias e vinculações, sistemas de classificação, identificação e desqualificação que, na forma de preconceitos, acompanham e caracterizam a controversa convivência por necessidade das diferentes disciplinas.

O resultado é que, diante de problemas críticos que não podem ser cobertos por apenas uma disciplina ou por um conjunto delas, parece impossível que elas possam se entender. Cada uma faz sua parte, mas não se cultiva a capacidade de organização diante de problemas sérios que só o conhecimento interdisciplinar pode enfrentar. O recente e doloroso exemplo da pandemia da covid-19 no mundo pegou de surpresa as verdades isoladas de cada disciplina. A forte relevância do conhecimento transversal, que não se esgota nas disciplinas, é fundamentada na EG pela teoria de sistemas complexos de Rolando García (2006). Piaget o convida para seu seminário semanal e para seus experimentos clínicos, operando uma demolição inclemente do empirismo lógico de Rolando García (formado com Rudolf Carnap e Hans Reichenbach), diante dos experimentos psicogenéticos que García não consegue explicar a partir de uma posição empirista. García converte-se assim, estudando em profundidade a EG, em um construtivista tão crítico que, logo depois, aponta para Piaget algumas das áreas não 
construtivistas de seu edifício teórico. Desde esse momento, até sua morte, em 1980, Piaget trabalharia muito próximo de García.

Com destaque, escrevem juntos Psicogênese e História da Ciência, em que argumentam que os mecanismos construtivos do conhecimento têm uma continuidade funcional ao longo do tempo e são os mesmos que operam tanto no desenvolvimento psicogenético das crianças quanto na história da criação dos conceitos de cada ciência. No mesmo trabalho, García introduz o conceito de marco epistêmico (Piaget \& García, 1982, p. 228), com o qual mostra que os problemas e questões que condicionam o desenvolvimento da ciência surgem de uma tomada de posição ideológica, na melhor das hipóteses política, diante dos problemas. Não faltam valores na ciência. Um marco epistêmico condiciona o tipo de perguntas que podem ser feitas em um determinado tempo, mas não determina o conteúdo da ciência.

Isso abre, assim, outra maneira de entender a objetividade imaculada e pura que a ciência empirista prega. Esse conceito ajuda a entender o motor das chamadas revoluções científicas, que não dependem de um aparato ou dispositivo tecnológico (o telescópio, o microscópio eletrônico etc.), mas do tipo de perguntas que guiam a pesquisa. Ao contrário do que se pode pensar, a cientificidade de uma investigação não depende das técnicas ou dos métodos, mas das questões com as quais investigamos (González \& Krohling-Peruzzo, 2019, p. 529).

A obra de Rolando García (2000), O Conhecimento em Construção. Das Formulações de Jean Piaget à Teoria dos Sistemas Complexos, consolida o amadurecimento da Epistemologia Genética, além de outras de suas contribuições, elevando a compreensão do conhecimento como um sistema complexo.

Em suma, García chegou a Genebra e conheceu Piaget sendo já um físico reconhecido da atmosfera, um empirista lógico de primeira qualidade, um gestor universitário que sempre procurou promover a ciência comprometida com as condições de sua Argentina natal e da América Latina. Ele retorna da Europa como um epistemólogo agudo e crítico, que colabora e capacita Piaget para a consolidação dessa nova disciplina. Rolando García passou os últimos anos de sua vida produtiva trabalhando no México, e lá publicou sua teoria de sistemas complexos como uma concretização de uma teoria geral dos processos de conhecimento (García, 2006).

\section{FREIRE COM PIAGET, PIAGET COM FREIRE?}

Os nomes e o brilho de Piaget e Freire dentro do mundo acadêmico são enormes. Centenas de versões podem ser encontradas, algumas mais bem fundamentadas do que outras, sobre suas contribuições para os processos de conhecimento (Piaget) e para os processos de alfabetização que levam à 
conscientização dos oprimidos sobre sua própria condição, seu passado e seu futuro possível (Freire). Além disso, como tudo na ciência, suas ideias e obras sofrem leituras rígidas, descontextualizadas e reducionistas.

Os avanços da Epistemologia Genética são amplamente compatíveis com as formulações conceituais e a prática que Freire desenvolve em seu trabalho como praticante e, ao mesmo tempo, formulador conceitual dos processos de alfabetização. Inclusive, me parece que eles ajudam a entender melhor e de forma mais crítica muitas das decisões e estratégias que Freire desenvolve em sua prática pedagógica, e algumas outras que não chegaram a avançar e que ainda estão sendo desenvolvidas em vários países do mundo. Paulo Freire tem sido conhecido principalmente como um pedagogo ativista lutando por justiça e democracia. Cicilia Krohling-Peruzzo, junto a outros autores, o situa nas origens do desenvolvimento da técnica de pesquisa/ação (González \& Krohling-Peruzzo, 2019, p. 475). Jean Piaget era um cientista em tempo integral, conhecido como pedagogo e psicólogo infantil, que constrói uma teoria revolucionária muito poderosa, mas despercebida ou mal interpretada sobre os processos de construção do conhecimento. Acreditamos que ambas as perspectivas podem dialogar de forma útil. Freire conhecia o trabalho das primeiras formulações de Piaget, mas nunca se dedicou a trabalhar em profundidade nessa vertente nem a desenvolver uma perspectiva científica própria. Não era o seu campo. As condições sócio-históricas em que viveu marcaram os limites do possível e do provável em seu trabalho. O mesmo acontece com Piaget. Ele provavelmente sabia algo do trabalho de Freire, mas sua paixão por criar uma teoria robusta, que acabaria com mistificações empiristas e inatistas sobre o conhecimento, não permitia que tivesse muito tempo para outras coisas. Para nós, o trabalho seminal de Paulo Freire é totalmente apoiado por uma teoria científica do conhecimento como ação que sustenta os princípios básicos de sucesso da operação de sua pedagogia. Ambas as perspectivas são encontradas na investigação e desenvolvimento de cibercultur@.

\section{CIBERCULTUR@ NO CAMINHO DE ALGUMAS VEREDAS QUE SE BIFURCAM}

Os mecanismos construtivos para conhecer/agir sobre o mundo nunca param seu movimento dialético. Em outras palavras, nossa espécie nunca deixa de conhecer.

A disciplina de Piaget e García não chega a estudar o desenvolvimento cognitivo de adultos comuns que já constroem abstrações reflexivas e inferências complexas para agir em seu mundo. Eles dificilmente o consideram porque não precisam, nem se tornarão profissionais na criação de conhecimento sobre 
um domínio. Em condições normais, a grande maioria da população adulta não está interessada ou envolvida com a ciência.

Nem a ciência está muito interessada nelas ou neles. Muito menos os analfabetos. Isso me parece uma clara lacuna no desenvolvimento da teoria. Piaget se concentrou especialmente nas crianças, pois, nessa idade, a força da criação, estruturação e desestruturação do conhecimento é enorme e nos permite estudar esses mecanismos comuns a todas e todos, de forma mais clara. No mundo social adulto, uma vez que são criadas estruturas cognitivas e gerenciais mais complexas, o potencial criativo parece declinar. Aparentemente, há menos construção de conhecimento do que desenvolvimento dele, e Piaget não teve a possibilidade de dedicar tempo e recursos a esse veio. Conhecer é aprender a diferenciar aquilo que nossa estrutura não era capaz de diferenciar anteriormente e, ao mesmo tempo, é aprender a integrar essas novas diferenças construídas dentro de estruturas mais complexas que nos permitem agir de forma diferente em nossa realidade. Se não conseguirmos diferenciar e integrar melhor, não poderemos agir de forma mais inteligente para mudar as condições que não queremos.

No México e na América Latina (e em todas as sociedades que foram globalizadas a partir de fora e pela força, os chamados periféricos, ou, mais recentemente, o sul global), há milhões de homens e mulheres historicamente empobrecidos e miserabilizados, não apenas na produção econômica, mas também em suas ecologias simbólicas. Ao longo dos séculos, desenvolveram uma autopercepção heterodeterminada (González, 2019, p. 99), definida de fora por outros, que Freire chama de opressores. A rede de relações simbólicas em que esse tipo de percepção é tecida é um dos nós interligados da relação hegemonia-subalternidade. Esses adultos, apesar de terem todo o potencial reflexivo já construído bio-psico-socialmente para atuar no mundo, ainda não conseguem diferenciar e integrar os componentes, as relações e as transformações de seu ser social em devir, em movimento, em processo. Muitos também falharam em se apropriar do poderoso artefato cultural que é a tecnologia de alfabetização.

Da mesma forma que com Piaget e García, o trabalho de Freire também sofre simplificações e reducionismos variados:

Sou contra Paulo Freire porque não aprecio os benefícios da palavra geradora?: "O Freire que tem circulado de boca a boca e de citação em citação ao redor do mundo é um Freire simplificado, formulado, unilateralizado, estereotipado a partir de um conjunto de noções fixas - educação bancária, alfabetização, educação de adultos, conscientização, diálogo, palavra geradora - e virtualmente fixado nos anos 60-70, junto com seus dois primeiros livros" [citando Rosa María Torres]. As melhores experiências que conheço da alfabetização de adultos por meio de 


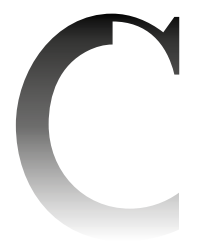

${ }^{2}$ A epigenética da cultura sustenta que as condições de pobreza, violência e estresse permanente são herdadas, não geneticamente, mas através da transformação da estrutura das mitocôndrias em processos agudos de metilação (Jablonka, 2016). Uma maneira importante de explorar a reprodução de algumas das condições mais agudas de pobreza e uma perspectiva poderosa para explorar no campo da análise social.

textos foram realizadas por grupos brasileiros, que vêm de uma prática anterior, ancorada nas teorias de Paulo Freire. (Ferreiro, 2007, p. 321)

Ainda outros, apesar de já terem sido alfabetizados, não parecem aproveitar essa capacidade de ler e escrever sua palavra, sua voz, sua versão e sua visão da modificação nas relações sociais que os colocaram onde estão. Esta condição é totalmente funcional para a ordem injusta das coisas, mas em congruência com todo o desenvolvimento das ideias de EG, temos certeza de que ela poderia ser mudada. Se perguntasse a Rolando García, “isso é possível?”, ele diria: "Isso não é possível. Você tem que construir o possível", e isso me parece o lugar da comunicação para a mudança social.

Se usarmos as ideias de Freire (1968/2005) para descrever o que ele chama de "níveis de consciência" dos oprimidos, a questão epistemológica seria, como você passa de um nível de consciência para outro? O que muda, o que se modifica, o que permanece intacto e o que há de novo? Uma consciência que opera em um modo intransitivo (pouco diferenciando-se de seu ser social) é “impermeável a desafios localizados fora da órbita vegetativa” (p. 60). Persiste repleta de superstições e naturalizações de processos sociais, é incapaz de se organizar com os outros para melhorar suas condições, opera centrada em si mesma e imersa em uma cultura de silêncio, e acaba sendo depressiva e tendo dificuldades em identificar e comunicar suas emoções ${ }^{2}$. O método de Freire, aprimorado à luz da EG, poderia ajudar a modificar coletivamente uma condição cultural e social em que os explorados, os oprimidos, não sabem que não sabem. Mas podem saber.

A mudança daí até uma consciência transitiva implica que alguma capacidade já foi construída para ir e agir além do imediato e, portanto, é capaz de gerar organização para se orientar em direção às mudanças sociais e políticas coletivas favoráveis. A partir dessa segunda forma de consciência, passar para uma consciência transitiva e crítica significa tornar-se capaz de integrar diferenças anteriormente despercebidas, que nos permitem construir interpretações mais profundas e densas dos problemas que os afligem e dos quais conseguem gerar uma representação diferenciada de suas causas concretas.

$\mathrm{O}$ que Freire descreve de forma filosófica e metafórica a partir de sua reflexão sobre as experiências de conscientização com centenas de homens e mulheres oprimidos de diferentes partes do mundo merece um trabalho rigoroso de sistematização e um processo de homologação conceitual com a ciência de Piaget e García, que não podemos assumir agora.

Organizando-se para construir o conhecimento de seu ser social, iniciam-se processos de empoderamento dos sujeitos. Especialmente aqueles que foram concebidos e tratados como meros objetos de estudo e não como sujeitos ativos 
do conhecimento. Essa é uma das consequências mais importantes do legado de Paulo Freire, não só no Brasil, mas no mundo.

Mas o que significa tornar-se sujeitos do conhecimento? Os atores sociais que podem enfrentar seus problemas construindo seu próprio conhecimento realmente se empoderam? A teoria e os achados da Epistemologia Genética nos oferecem uma poderosa ferramenta científica, conceitual e metodológica para analisar experiências de conscientização como processos de empoderamento.

Observar, gravar, identificar, analisar e dialogar coletivamente sobre a especificidade de sua inserção no mundo da produção de valor (como explorados), da organização social (como dominados), de representações, tradições e símbolos (como subalternos) é uma tarefa diária que nos permite reorganizar e redesenhar nossas ecologias simbólicas (González, 2019). O método de Freire para alfabetização de adultos ainda está vivo, não se cristalizou, e agora pode ser fundamentado e criticado à luz de uma interpretação científica (ou seja, histórica, dialética, aberta e documentada) dos processos de construção do conhecimento. Toda a teoria científica prova sua potência quanto mais gera questões que a forçam a avançar e explorar áreas que não havia coberto antes ou que apenas diferenciou parcialmente. O trabalho de desenvolvimento da cibercultur@ se preocupa em investigar e promover o crescimento das capacidades de conhecer o mundo, atuando não apenas na situação específica que causa o que as pessoas vivem e identificam como um problema, mas sobre a forma simbólica e prática de abordá-lo e possibilitar a capacidade de transformar suas ecologias simbólicas.

Com a noção de "ecologias simbólicas" designamos todo o conjunto de relações de sentido que, em uma sociedade, são construídas na história com um ambiente físico, biológico, psicológico, social e cultural, por meio da atividade cognitiva e suas dimensões mais complexas, como a mente, o discurso e a modelagem e a atividade adaptativa das identidades e alteridades dos diferentes e variados coletivos sociais. (González, 2019, p. 209)

A informação, a comunicação e o conhecimento são três componentes fundamentais para o desenvolvimento, a derivação e o entendimentos dessas ecologias simbólicas. Esses três componentes são tecidos juntos por relações $d e$ interdefinibilidade, de tal forma que a especificidade das propriedades e características de cada um depende de sua relação com os outros dois. Não podem ser estudados separadamente. Ao estudar e praticar a comunicação para a mudança social, o status conceitual da Informação, da Comunicação e do Conhecimento deve ser tomado como um conjunto de forças e estruturas móveis de um processo complexo que inclui transformações biológicas, comportamentais e sociais. 
${ }^{3}$ Ver o trabalho de Antonio Paoli (2014) e a pedagogia da valorização mútua com alunos do ensino fundamental no México.
Essas transformações melhoram a capacidade individual e do grupo de diferenciar e integrar (ou seja, conhecer) em ação suas experiências do mundo e, ao fazê-lo, aumentar a capacidade dos indivíduos e grupos agirem, enfrentarem e superarem suas condições e contradições sociais.

Quando um certo grupo de pessoas, que sofre e padece de problemas críticos em sua vida cotidiana (fome, furacões, maremotos, violência familiar, insegurança social, precariedade e exploração do trabalho, depressão, desnutrição, pandemias, discriminação etc.), começa a cultivar e construir seu próprio conhecimento, se conscientiza. Esse grupo ativa um processo de empoderamento que recupera historicamente sua capacidade de fazer e modificar as condições de sua vida, tanto em termos materiais quanto sociais e simbólicos. É disso que se trata desenvolver cibercultur@.

Quando começa o processo de reconstrução e apropriação de seus sistemas de informação, seus sistemas de coordenação e comunicação, juntamente com seus sistemas de conhecimento, ativados por um trabalho de elaboração e reformulação dialógica em suas concepções e seus processos, torna-se possível recuperar ou conquistar a capacidade de narrar a si mesmos e direcionar sua ação coletiva para a resolução de seus problemas críticos.

Essa capacidade de se autonarrar pode ser recuperada, habilitada e objetivada em três dimensões estratégicas. A saber, para aumentar a capacidade do grupo de elaborar um discurso coerente e próprio sobre seu passado; para aprimorar sua especialidade e oportunidade de gerar suas próprias definições, sensíveis e bem documentadas de sua situação atual; e particularmente, na vontade de abrir o futuro para vários mundos possíveis ${ }^{3}$.

A luta para desocupar seus territórios simbólicos, que foram e permanecem ocupados, passa necessariamente pelo redesenho dessa relação tridimensional com: (1) informação, entendida não como as notícias, mas como a capacidade de estabelecer relações entre as coisas, eventos e pessoas organizadas, com signos e textos cada vez mais complexos que se tornam significativos, o que antes não podiam fazer; (2) comunicação, entendida não como enviar mensagens e recebê-las, mas como a capacidade de coordenar ações com os outros, ou seja, se auto-organizar, e (3) conhecimento, esse processo de assimilar e acomodar o mundo que nos transforma, ao mesmo tempo que o transformamos, quando aumentamos a capacidade de diferenciar e integrar, como produto de abstrações reflexivas de que são capazes os indivíduos e o coletivo, com maiores graus de autodeterminação e inteligência.

A Epistemologia Genética desenvolveu uma teoria científica rigorosa e pertinente para entender esses processos. A pedagogia de Freire trabalha precisamente com aqueles que não foram incluídos na história de consolidação dessa disciplina. Ambas estão em plena evolução. 
A pesquisa e o desenvolvimento da cibercultur@, ou seja, da capacidade de autodeterminação que pode ser cultivada e desenvolvida com os processos de conhecimento, potencializada pela organização e inteligência coletiva, é o desafio que há algumas décadas começamos a enfrentar, tentando ver um pouco mais longe, montado nos ombros de gigantes. Sabemos muito bem que o que desejamos não é possível. Teremos que construir o possível.

\section{REFERÊNCIAS}

Bachelard, G. (1981). El nuevo espiritu científico. Nueva Imagen.

Badenes, D. (2020). Mapas para una historia intelectual de la comunicación popular

[Tese de doutorado, Universidad Nacional de La Plata]. Repositorio Institucional de la UNLP. https://bit.ly/3kkVtaA

Becker, F. (2017). Paulo Freire e Jean Piaget: Teoria e prática. Schème. Revista Eletrônica de Psicologia e Epistemologia Genéticas, 9(N. Esp.), 7-47. https://doi.org/10.36311/1984-1655.2017.v9esp.02.p7

Boff, L. (2014). Saber cuidar. Ética do humano - compaixão pela terra. Vozes.

Bunge, M. (1983) La investigación científica. Ariel.

Caldart, R. (2004). Pedagogia do Movimento Sem Terra. Expressão Popular.

Dale, J., \& Hyslop-Margison, E. (2010). Paulo Freire: Teaching for freedom and transformation. The philosophical influences on the work of Paulo Freire. Springer. https://doi.org/10.1007/978-90-481-9100-0

Downing, J. (2021). Radical media. Comunicación rebelde y movimientos sociales (Colección Medios\&Redes). Universidad Nacional de Quilmes.

Dussel, E. (1998). Ética de la liberación en la edad de la globalización y de la exclusión. Trotta.

Ferreiro, E. (2007). Alfabetización de niños y adultos. Textos escogidos. Crefal. https://bit.ly/2WjSs2c

Freire, P. (1973). La educación como práctica de la libertad. Siglo XXI.

Freire, P. (1993). Pedagogía de la esperanza. Siglo XXI.

Freire, P. (2005). Pedagogía del oprimido (55a ed., Novo formato). Siglo XXI. (Trabalho original publicado em 1968)

Freire, P. (2010). Pedagogia da autonomia. Saberes necessários à prática educativa. Paz e Terra. (Trabalho original publicado em 1996)

García, R. (2000). El conocimiento en construcción. De las formulaciones de Jean Piaget a la teoría de sistemas complejos. Gedisa.

García, R. (2006). Sistemas complejos. Conceptos, método y fundamentación epistemológica de la investigación interdisciplinaria. Gedisa. 
García, R. (2008). Dialéctica, psicogénesis e historia de las ciencias. In J. Piaget, Las formas elementales de la dialéctica (pp. 201-216). Gedisa.

González, J. A. (2019). Entre cultura(s) y cibercultur@(s). Incursiones y otros derroteros no lineales (3a ed.). Centro de Investigaciones Interdisciplinarias en Ciencias y Humanidades, Universidad Nacional Autónoma de México. https://bit.ly/2XVm8TV

González, J. A. (Coord.) (2018). No está muerto quien pelea. Homenaje a la obra de Rolando García Boutigue. Centro de Investigaciones Interdisciplinarias en Ciencias y Humanidades, Universidad Nacional Autónoma de México. https://bit.ly/3B8WSIe

González, J. A., \& Krohling-Peruzzo, C. (Eds.). (2019). Arte y oficio de la investigación científica. Cuestiones epistemológicas y metodológicas. Ciespal.

Gumucio, A., \& Tufte, T. (2008). Antología de la comunicación para el cambio social. Lecturas históricas y contemporáneas. Consorcio de Comunicación Social.

Jablonka, E. (2016). Cultural epigenetics. The Sociological Review Monographs, 64(1_suppl), 42-60. https://doi.org/10.1111/2059-7932.12012

Krohling-Peruzzo, C., \& González, J. A. (2018). Agroecología y antroponomía en movimientos sociales de Brasil. INTERdisciplina, 6(14), 205-235. https://doi.org/10.22201/ceiich.24485705e.2018.14.63387

Paoli, A. (2014). Pedagogía del mutuo aprecio. Didácticas del programa Jugar y vivir los valores (2a ed.). En los zapatos del otro, Universidad Autónoma Metropolitana.

Piaget, J., \& García, R. (1982). Psicogénesis e historia de la ciencia. Siglo XXI. Piaget, J. (1973). La formación del símbolo en el niño. Fondo de Cultura Económica. Tufte, T. (2017). Communication and social change. A citizen perspective. Polity Press. Vygotski, L., \& Luria, A. (2007). El instrumento y el signo en el desarrollo de niño (P. del Río \& A. Álvarez, Eds.). Fundación Infancia y Aprendizaje.

Artigo recebido em 29 de junho de 2021 e aprovado em 3 de setembro de 2021. 